IDEAs in Ectgagy AND Evalution 10: 47-54, 2017

doi:10.4033/iee.2017.10.9.c

(C) 2017 The Author. (C) Ideas in Ecology and Evolution 2017

Received 7 July 2018; Accepted 19 January 2018

Commentary

\title{
The demise of dinosaurs and learned taste aversions: The biotic revenge hypothesis
}

\author{
Michael J. Frederick and Gordon G. Gallup, Jr. \\ Michael J. Frederick (mfrederick@ubalt.edu), Division of Applied Behavioral Sciences, University of Baltimore, \\ Baltimore, Maryland, USA 21201 [corresponding author] \\ Gordon G. Gallup, Jr. (ggallup@albany.edu), University of Albany, State University of New York, Albany, New \\ York, USA
}

\begin{abstract}
Numerous hypotheses have been advanced to explain the worldwide extinction event that led to the disappearance of the dinosaurs. There is considerable empirical support for the well-known asteroid impact hypothesis, and volcanic eruptions in the Deccan Traps have also been implicated. Increasingly, theories involving multiple causes are being considered, yet few of these consider how the cognitive and behavioral abilities of certain classes of animals may have differed in ways that allowed some to survive while others perished. Here we advance the hypothesis along with supporting evidence that the emergence of toxic plants coupled with an inability to form learned taste aversions may have contributed to the extinction of dinosaurs.
\end{abstract}

Keywords: extinction; conditioned taste aversion; coevolution; angiosperms.

\section{Introduction}

The prevailing view of dinosaur extinction is that it occurred as a consequence of a biotic crisis occasioned by a colossal asteroid impact. This hypothesis was first advanced in the 1970's by a team of researchers led by Luis Alvarez (see Alvarez et al. 1980). There is a conspicuous layer of iridium between the Cretaceous period and the Tertiary period, which is identified by most researchers as the point when the dinosaurs went extinct. Although iridium is rare on this planet, it is common in meteoroids and asteroids. Thus, the observed layer of iridium is consistent with a colossal asteroid impact, which created the equivalent of what is known as a nuclear winter or "impact winter" (Vellekoop et al. 2016).

Several years ago, an interdisciplinary team of scientists attempted to anticipate the consequences of a major thermonuclear exchange (see Robock et al. 2007, Toon et al. 2007). The consensus was that if there ever was a major nuclear war, the ensuing nuclear winter would likely kill most of the creatures that had been spared by the explosions and radiation. Multiple nuclear explosions would force dust and debris into the upper atmosphere causing the planet to be enveloped by a dense cloud that would block sunlight, resulting in plummeting global temperatures. An extended period of several years would be required for the sediment to precipitate out of the atmosphere and the climate to recover and return to normal. If an asteroid of sufficient mass collided with Earth, there is reason to believe it would do the same thing, perhaps in an even more pronounced way. It is estimated that the asteroid that collided with planet Earth at about this time was about 6-7 miles wide before it entered the atmosphere (Alvarez et al. 1980). However, upon entering the Earth's atmosphere much of the mass would have been vaporized due to the extreme heat caused by air friction. There is consensus that the Yucatan Peninsula is where the impact happened, and that an area about onehundred miles in diameter known as Chicxulub represents the remains of the resulting crater (Hildebrand et 
al. 1991, Schulte et al. 2010). The subsequent loss of numerous plant and animal species on Earth is referred to as the Cretaceous-Tertiary (K-T) or CretaceousPaleogene (K-Pg) extinction event (see Gradstein et al. 2004).

The asteroid impact hypothesis implies that the effects should have been both widespread and abrupt. Therefore, if the demise of the dinosaurs was occasioned by a colossal asteroid impact of this magnitude the fossil record should be very clear in revealing a sudden disappearance of dinosaurs. It would also imply that not only dinosaurs would have been adversely affected, but that many other creatures would have followed suit. The evidence, however, suggests that dinosaurs began going extinct before the asteroid impact ("Extinction-The Asteroid-impact," 2016), and Sloan et al. (1986) have argued that the disappearance of dinosaurs probably spanned a period of at least seven million years. While other species and groups, such as mammals, were clearly affected by the asteroid impact, no terrestrial fauna were as profoundly affected as the dinosaurs (MacLeod et al. 1997). Thus, rather than being sudden and widespread, the mass extinction appears to have been something that happened in a more gradual way, and that affected some species more than others.

An additional factor that has received considerable attention was the volcanic eruption of the Deccan Traps in India. These eruptions are thought to have caused considerable disruption to the climate over a period of several hundreds of thousands of years leading up to the asteroid impact (Schoene et al. 2015). This gradual ecological deterioration would have placed many species under stress. When the asteroid impact occurred, these vulnerable species may have been at even greater risk of extinction (Scheone et al. 2015). More recently, Erickson et al. (2017) have suggested that climate change could have had a particularly pronounced impact on the dinosaurs during this time due to the lengthy incubation periods of their eggs.

Here we advance a behavioral hypothesis for this event that was initially articulated by Gallup and Suarez (1987), and evaluate it using available paleontological and experimental evidence, while also delineating some predictions that could be tested with contemporary research. According to this alternative hypothesis, the demise of the dinosaurs occurred not simply as a consequence of a biotic crisis, but also a biotic "revenge" that occurred in the context of plantherbivore interaction.

\section{Conditioned Taste Aversions}

Plant adaptations to herbivory include morphological features like barbs, thistles, and thorns which deter consumption, and encasing their genetic material in shells that are less accessible to animals. Many plants have also evolved chemical defenses that enable some plants to create noxious odors, aversive tastes, or toxic chemicals that can be harmful or even lethal if consumed. Some plants, such as hot chili peppers, produce compounds that selectively deter consumption by mammals, but do not deter birds who act as more effective seed dispersers (Tewksbury and Nabhan 2001). Laycock (1978) has suggested that large herbivores would have been subject to natural selection in response to the emergence of poisonous plants and are likely to have coevolved behavioral strategies for detecting and avoiding them.

Our particular focus here is on plants that make predators sick by creating gastrointestinal distress. Provided that the effect is not lethal, this adaptation only functions as an effective predator defense if the animal can learn to associate the gastro-intestinal consequences of consuming a toxic plant with salient features of the plant, so the animal can learn to avoid it in the future. This involves what psychologists call learned, or conditioned, taste aversions (Garcia et al. 1955).

To appreciate the importance of learned taste aversions, consider the continuing attempts to eliminate rats despite varying degrees of success. The reason it is often not successful is because of several unique adaptations that rats and other animals have evolved to cope with plant toxicity. Rats must be particularly careful about what they eat because they are unable to regurgitate (see Horn et al. 2013). Upon ingesting something toxic they must simply endure the resulting illness until the toxins pass inexorably through their gastro-intestinal track. Not surprisingly, rats demonstrate ingestional neophobia (Best and Batson 1977), so that when rats encounter a new and novel food they typically sample a small amount, which, in the case of rat poison, is often a sub-lethal dose. If they get sick from the novel food, rats show an exceptional capacity, after only a single trial, to associate the taste and smell of that food with its aversive gastro-intestinal consequences (Garcia et al. 1955). Consequently, rats develop learned taste aversions to the food in question. Subsequent work has demonstrated that these acquired taste aversions occur in many other species as well (Wilcoxon et al. 1971, Lett 1980).

Researchers have studied learned taste aversions in many different species using poisoning paradigms under controlled laboratory conditions, often using chemicals such as apomorphine or lithium to create gastrointestinal stress. When animals are exposed to novel food and made sick they typically develop a robust learned taste aversion after a single trial and avoid eating that food in the future (Nowlis et al. 1980). This is contrary to many other instances of classical conditioning that require that multiple paired presentations of the conditioned and unconditioned stimuli. As evidence for just how specialized 
these learned taste aversions are rats exposed to a novel flavor and subsequently anesthetized and rendered unconscious before becoming sick show a robust learned taste aversion upon recovery from anesthesia that occurs in the absence of conscience processing (Roll and Smith 1972).

As further evidence for just how specialized these associations are, learned taste aversions are unaffected by retrograde amnesia (see Kral and Beggerly 1973). Retrograde amnesia impairs recent memory, and under laboratory conditions retrograde amnesia can be induced experimentally using electroconvulsive shock. Animals given electroconvulsive shock following traditional conditioning trials show no evidence the next day of a learned association. For learned taste aversions, however, the application of electroconvulsive shock only disrupts the learned association if it is presented within five minutes following the conditioning trial (Kral and Beggerly 1973). This suggests that anterograde, but not retrograde, amnesia can disrupt conditioned taste aversions (Kral and Beggerly 1973).

Further evidence that these associations are highly specialized involves the amount of time separating exposure to a novel food and the onset of illness. Animals that consume toxic foods often do not get sick until a half hour to an hour later. Thus, during the interstimulus interval (the period separating taste and ingestion from the onset of malaise) they are likely to ingest other familiar foods, which puts these familiar foods in much closer temporal proximity to the onset of illness. This would suggest that an aversion to the familiar food would become the most robust, but a variety of creatures are contra-prepared to associate familiar food with gastro-intestinal distress, and highly prepared or predisposed to associate novel food with eventual gastro-intestinal distress (see Randich and LoLordo 1979).

As an example of this capacity in humans, consider the case of intoxication. Alcohol induced conditioned taste aversions are well documented (Risinger and Cunningham 1998). A hangover can be considered a gastro-intestinal aversive outcome of over-indulging in alcohol. When novices over-indulge and get sick on a specific alcoholic beverage, they often develop robust learned taste aversions to that particular beverage. This can happen even if they become unconscious before they get sick. When this occurs, it is analogous to being anesthetized before one gets sick. Such individuals are still likely to retain these learned taste aversions, so that upon recovering from the hangover, even the taste or smell of the alcoholic beverage that made them sick triggers conditioned malaise and nausea. Thus, they often find that they cannot entertain the possibility of drinking what made them sick. However, after this event their ability to drink other alcoholic beverages is left unaffected. This indicates that they do not develop an aversion to the substance of that made them sick, but rather to the taste and smell of what made them sick. Similarly, cancer patients who become nauseated by chemotherapy often develop strong aversions to foods consumed shortly before or after the treatments (Jacobsen et al. 1993). Moreover, the development of specific aversions in humans to the taste and smell of what made them sick can occur in a single trial and last a lifetime (Seligman and Hager 1972).

\section{The Biotic Revenge hypothesis}

Dinosaurs existed in a variety of different forms, including herbivorous, omnivorous, and carnivorous species. Some of the herbivorous dinosaurs were among the largest creatures ever to have lived on land. The massive Argentinosaurus huinculensis measured up to 130 feet in length and weighed as much as 212,000 pounds (González et al. 2016). These large herbivorous dinosaurs could have generated strong selection pressure for the development and evolution of toxic and chemical defenses by plants. According to our hypothesis, the evolution of the widespread and highly specialized ability to form learned taste aversions was an adaption to the emergence of plant toxicity. However, dinosaurs may have been incapable of learning to associate toxic plants with tastes and smells, leading them to consume harmful or eventually lethal doses of toxic plants. We suggest that this inability placed additional strain on these species. Thus, while events such as an impact winter and climate change could have affected many terrestrial plants and animals, the emergence of new toxins in angiosperm plants may have done particular damage to dinosaurs.

Prior to the emergence of toxic angiosperms, large terrestrial herbivores required vast quantities of plants to satisfy their massive caloric energy needs, which may have led to relatively indiscriminate feeding habits. While smaller herbivores may have been able to selectively avoid certain plants once alkaloid toxins appeared, such selectivity may not have been a viable option for larger dinosaurs due to the sheer volume of plants they needed to consume to survive. Thus, while conditioned taste aversions may have been acquired by smaller dinosaur species, some of whom became the descendants of modern birds, larger herbivores could have been unlikely to develop such discrimination because of the need to ingest sufficient quantities of food. Therefore, large, terrestrial herbivores could have been disproportionately impacted by the evolution of plant toxins. Smaller herbivores may have become more discriminant in their feeding habits, while aquatic reptiles may not have had to contend with the same array of new toxins. At the same time, mammals may have benefited from an increasing variety of edible fruits made available by the spread of the angiosperms, 
which might have placed the less frugivorous dinosaurs at a competitive disadvantage.

If plant toxicity is at least partly to blame for the disappearance of the herbivorous dinosaurs, what about carnivorous species, such as Tyrannosaurus rex? It is important to realize that the livelihood of carnivorous dinosaurs, particularly larger ones, was dependent upon the presence of herbivorous dinosaurs as a source of food. Therefore, if the herbivorous dinosaurs went extinct, large carnivorous dinosaurs would have followed suit.

\section{Supporting Evidence}

Plants. The first flowering plants, or angiosperms, appear in the fossil record well before the asteroid impact. The proliferation of angiosperms during the Cretaceous period was accompanied by a series of speciation events in both plants and the insects that pollinate and/or prey upon them (Ehrlich and Raven 1964). Although there continues to be uncertainty about precisely when plants first evolved toxic defenses, this period of angiosperm proliferation would seem to be a strong candidate case. Note that the appearance of toxic plants would not produce widespread effects immediately, as it would take considerable time for these plants to spread and eventually proliferate to different parts of the planet. In keeping with this, the fossil record indicates dinosaurs likely disappeared over a more gradual period lasting at least seven million years, rather than abruptly disappearing (Sloan et al. 1986, Sakamoto et al. 2016). Although many species were affected, in contrast to dinosaurs all major mammalian lineages, including monotremes (egg-laying mammals), multituberculates, marsupials and placentals, dryolestoideans, and gondwanatheres survived the K-T extinction event, despite suffering losses (Gelfo and Pascual 2001).

The relative co-occurrence of angiosperm proliferation and the disappearance of the dinosaurs has not gone completely unnoticed. Tony Swain, a biologist working at the Royal Botanic Gardens, suggested that the development of alkaloid toxins in flowering plants could have made much of the available vegetation unpalatable or toxic to the dinosaurs, and may have precipitated their extinction (Swain 1976) ${ }^{1}$. He also noted evidence suggesting that tortoises and diamondbacked terrapins are much less sensitive to bitter tastes than mammals (Burghardt 1970, as cited in Swain 1975). However, at the time this theory was dismissed because most available evidence suggested increased diversity among herbivorous dinosaurs during the height of angiosperms proliferation, rather than declining numbers of dinosaur species (see Russell 1979). Thus, the dinosaurs were thought to have thrived right up until a sudden event caused their rapid extinction.

On the other hand, considering the more complete fossil records now available, a number of researchers believe that the dinosaurs were in fact in decline over a much longer period leading up to the asteroid impact, one that may have lasted tens of millions of years (Sakamoto et al. 2016). Of particular note is the observation that two groups of dinosaurs, the Hadrosauriforms and the Ceratopdisae, seem to have fared better than the others (Sakamoto et al. 2016). These groups also have particularly powerful jaws and dental batteries, allowing them to process tougher, nonangiosperm plant food, which may have enabled them to avoid the newly evolved alkaloid toxins in flowering plants (Sakamoto et al. 2016).

Crocodilians. One way to test our hypothesis is to focus on crocodilians, which includes crocodiles in Africa, Asia, and Australia along with North American alligators, and their South American counterpart, caimans. Crocodilians are descendent from the precursors to, not only dinosaurs, but pterosaurs as well. Based on this connection, Gallup and Suarez (1987) examined crocodilians for their capacity, or lack thereof, to form learned taste aversions. Since crocodilians are descendent from the same creatures that gave rise to dinosaurs, this creates the opportunity to evaluate the tenability of the proposition that dinosaurs went extinct due to an inherent inability to learn to avoid eating toxic plants.

Ten caimans, each measuring 12 inches in length, were housed individually in a separate aquarium containing water, sand, gravel, and rocks to allow the animals to move in and out of the water. The diet of the animals consisted of beef cut it up into small pieces. After several months the caimans were then divided into two groups. Those in the experimental group were given chicken instead of beef for the very first time, and this was followed by an injection of apomorphine to induce sickness. The other five caimans were also injected with apomorphine, but were not fed chicken. Once both groups recovered from the apomorphine, they were tested for their response to chicken. The caimans appeared unaffected by the period of malaise. When tested those made sick in association with eating chicken were no less likely to eat chicken than those made sick without eating chicken. Thus, there was no evidence for the development of a specific learned taste aversion. As noted by Gallup and Suarez (1987), this evidence is consistent with the hypothesis that the demise of the dinosaurs entailed a biotic revenge engineered unwittingly by the natural selection of plants

\footnotetext{
${ }^{1}$ In an earlier paper, Koch (1967) posited that the decay of selenium bearing rocks during the Mesozoic Era gave rise to seleniferous plants that may have poisoned the dinosaurs.
} 
to deal with animals as plant predators. These data are consistent with the gradual disappearance of dinosaurs and the specific effects on dinosaurs to the exclusion of other reptiles, mammals, and even birds. One reason crocodilians did not go extinct is that being aquatic carnivores they never had to cope with the problems posed by consuming toxic terrestrial plants.

Birds. Birds represent an interesting test case because much of the available evidence suggests birds descended from dinosaurs. However, in contrast to caimans, birds are in fact capable of forming learned food aversions. Rather than forming taste aversions, birds develop aversions to the visual features of whatever made them sick. Several classic studies have been done with blue jays under laboratory conditions (see Brower and Moffitt 1974). In these studies jays are given the opportunity to eat monarch butterflies for the first time. These butterflies incorporate milkweed toxins into their bodies so that if they are eaten the animals get sick. After eating a monarch butterfly, the jays later show conditioned retching at the mere sight of a monarch butterfly. This suggests that birds may have survived extinction because of their ability to form learned visual food aversions.

Another factor that may have partially exempted birds from the problems posed by plant toxins is their subsistence on insects and seeds rather than plants. The most common feeding pattern among birds is insectivory, and nearly $80 \%$ of extant bird species include insects in their diet (see Klasing 1998). It is also important to note many herbivorous birds eat seeds (granivorous) instead of plants. Although some smaller dinosaurs are thought to have been insectivores, most were herbivores or large carnivores (Longrich and Currie 2009).

\section{Conclusions}

Although there is considerable empirical support for the asteroid impact hypothesis, the evidence is also consistent with the possibility that dinosaurs went extinct partly as a consequence of a specific behavioral deficit: an inability to form learned food aversions. We think this perspective can generate novel predictions that could be tested with existing fossilized evidence. For example, prehistoric insects that were entrapped in in the fossilized remains of tree sap, or amber, are a case in point. Insects captured in amber are surprisingly well preserved. Thus, people who work with amber fossilized insects would be in a prime position to analyze the presence of angiosperm and other plant toxins in fossilized hematophagous insects during the period of time that dinosaurs went extinct. The question would be whether there was a rise in angiosperm toxins among these blood-sucking fossilized insects sampled from that appropriate time period. It is also possible that angiosperm toxins could have become incorporated in skeletal features of herbivorous dinosaurs and might survive fossilization. If this were the case, one could analyze dinosaur bone fragments from the K-T boundary to see if they contain angiosperm toxins as well. As shown in Table 1, the taste aversion hypothesis is not only consistent with recently discovered evidence concerning the extinction of dinosaurs, it can also be used to make a number of additional testable predictions as well.

It is important to emphasize that our intent is not to criticize or discount existing theories pertaining to the extinction of the dinosaurs, but rather to add a complimentary perspective that takes behavior and coevolution into account. We have no reason to question the body of empirical work that has lent prior support to the asteroid impact hypothesis. It is clear that the environment was undergoing drastic changes during this period, with many species competing for scarce resources. However, under these circumstances, any additional disadvantage resulting from an inability to develop learned taste aversions may have been a contributing factor for the already threatened dinosaur species. It is our hope that paleontologists will consider this possibility when evaluating the fossil record in the future, and use these opportunities to further test our hypothesis using empirical evidence.

\section{Acknowledgements}

The authors thank Aron Wiegand, as well as the reviewers and editor, for providing suggestions on earlier drafts of this paper.

\section{Referees}

Glenn Geher - geherg@newpaltz.edu SUNY New Paltz

Omar T. Eldakar - oeldakar@ nova.edu NOVA Southeastern University 
Table 1. Confirmed predictions and testable hypotheses about dinosaur extinction based on a failure to develop learned taste aversions.

Prediction $\quad$ Cited Evidence

Confirmed Predictions

1) The disappearance of dinosaurs was gradual rather than sudden.

Sakamoto et al. (2016)

2) No terrestrial fauna have been as profoundly affected by conditions

Sloan et al. (1986)

surrounding the K-T boundary as dinosaurs.

MacLeod et al. (1997)

3) Allowing for the dispersal of angiosperms, the emergence of plant toxicity corresponds with the disappearance of dinosaurs.

Swain (1976)

4) Rather than being triggered by the asteroid impact, the disappearance of dinosaurs precedes the K-T boundary and extends for millions of years after.

Sakamoto et al. (2016)

Sloan et al. (1986)

5) Learned taste aversions are an adaptation to plant toxicity.

Gallup and Suarez (1987)

6) Learned taste aversions are a highly evolved specialized form of learning.

Garcia et al. (1955)

Kral and Beggerly (1973)

Roll and Smith (1972)

7) The capacity to form learned taste aversions is widespread among surviving terrestrial vertebrates.

See section on 'Conditioned

Taste Aversions' in the text.

8) Caimans as representative crocodilians descendant from dinosaurs Gallup and Suarez (1987) appear incapable of developing learned taste aversions.

\section{Additional Testable Hypotheses}

1) Because of being carnivorous and aquatic, other species of crocodilians (e.g. alligators and crocodiles) should also be incapable of forming learned taste aversions.

2) Fossilized remains of blood sucking insects that used dinosaurs as hosts may contain traces of plant toxins.

3) Small amounts of angiosperm toxins may exist in the bones of herbivorous dinosaurs.

\section{References}

Alvarez, L.W., Alvarez, W., Asaro, F., and H.V. Michel. 1980. Extraterrestrial cause for the Cretaceous-Tertiary extinction. Science 208(4448): 1095-1108. CrossRef

Best, M.R., and J.D. Batson. 1977. Enhancing the expression of flavor neophobia: some effects of the ingestion-illness contingency. Journal of Experimental Psychology. Animal Behavior Processes 3(2):132143. CrossRef

Brower, L.P., and C.M. Moffitt. 1974. Palatability dynamics of cardenolides in the monarch butterfly. Nature 249(5454):280-283. CrossRef

Burghardt, G.M. 1970. Chemical perception in reptiles. Advances in Chemoreception 7:241-308. CrossRef
Ehrlich, P.R. and P.H. Raven. 1964. Butterflies and Plants: A Study in Coevolution. Evolution 18(4): 586608. CrossRef

Erickson, G.M., Zelenitsky, D.K., Kay, D.I., and M.A. Norell. 2017. Dinosaur incubation periods directly determined from growth-line counts in embryonic teeth show reptilian-grade development. Proceedings of the National Academy of Sciences 114(3):540-545. CrossRef

Extinction - The Asteroid-impact Theory. 2016. Retrieved 2016 August 26 from http://science.jrank. org/pages/2643/Extinction-asteroid-impact-theory. $\underline{\text { html }}$

Gallup, G.G., Jr. and S.D. Suarez. 1987. "Biotic revenge" and the death of the dinosaurs. The Scientist, Jan. 26, p. 10. 
Garcia, J., Kimeldorf, D.J., and R.A. Koelling. 1955. Conditioned aversion to saccharin resulting from exposure to gamma radiation. Science 122(3160): $157-158$.

Gelfo, J.N., and R. Pascual. 2001. Peligrotherium tropicalis (Mammalia Dryolestida) from the early Paleocene of Patagonia, a survival from a Mesozoic Gondwanan radiation. Geodiversitas 23(3):369-379.

González Riga, B.J., Lamanna, M.C., Ortiz David, L.D., Calvo, J.O., and J.P. Coria. 2016. A gigantic new dinosaur from Argentina and the evolution of the sauropod hind foot. Scientific Reports 6:19165. $\underline{\text { CrossRef }}$

Gradstein, F.M., Ogg, J.G., and A.G. Smith, editors. 2005. A Geologic Time Scale 2004. Cambridge: Cambridge University Press. CrossRef

Hildebrand, A.R., Penfield, G.T., Kring, D.A., Pilkington, M., Camargo Z., A., Jacobsen, Sand W.V. Boynton. 1991. Chicxulub Crater: A possible Cretaceous/Tertiary boundary impact crater on the Yucatán Peninsula, Mexico. Geology 19(9):867-871. CrossRef

Horn, C.C., Kimball, B.A., Wang, H., Kaus, J., Dienel, S., Nagy, A. et al. 2013. Why can't rodents vomit? A comparative behavioral, anatomical, and physiological study. PLoS ONE 8(4):1-16. CrossRef

Jacobsen, P.B., Bovbjerg, D.H., Schwartz, M.D., Andrykowski, M.A., Futterman, A.D., Gilewski, T., et al. 1993. Formation of food aversions in cancer patients receiving repeated infusions of chemotherapy. Behaviour Research and Therapy 31(8):739-748. CrossRef

Klasing, K.C. 1998. Comparative Avian Nutrition. New York, NY, US: CAB International.

Koch, N. 1967. Disappearance of the dinosaurs. Journal of Paleontology 41(4): 970-972.

Kral, P.A., and H.D. Beggerly. 1973. Electroconvulsive shock impedes association formation: Conditioned taste aversion paradigm. Physiology \& Behavior 10(1):145-147. CrossRef

Laycock, W.A. 1978. Coevolution of poisonous plants and large herbivores on rangelands. Journal of Range Management 35(5):335-342. CrossRef

Lett, B.T. 1980. Taste potentiates color-sickness associations in pigeons and quail. Animal Learning \& Behavior 8(2):193-198. CrossRef

Longrich, N.R., and P.J. Currie. 2009. Albertonykus borealis, a new alvarezsaur (Dinosauria: Theropoda) from the Early Maastrichtian of Alberta, Canada: implications for the systematics and ecology of the Alvarezsauridae. Cretaceous Research, 30(1):239252. CrossRef

MacLeod, N., Rawson, P.F., Forey, P.L., Banner, F.T., Boudagher-Fadel, M.K., Bown, P. R., et al. 1997. The Cretaceous-Tertiary biotic transition. Journal of the Geological Society 154(2):265. CrossRef
Nowlis, G.H., Frank, M.E., and C. Pfaffmann. 1980. Specificity of acquired aversions to taste qualities in hamsters and rats. Journal Of Comparative And Physiological Psychology 94(5):932-942. CrossRef

Paul, G.S. 2010. The Princeton Field Guide to Dinosaurs. Princeton, NJ, US: Princeton University Press.

Robock, A., Oman, L., Stenchikov, G.L., Toon, O.B., Bardeen, C., and R.P. Turco. 2007. Climatic consequences of regional nuclear conflicts. Atmospheric Chemistry and Physics 7: 2003-2012. CrossRef

Randich, A., and V.M. LoLordo. 1979. Associative and nonassociative theories of the UCS preexposure phenomenon: Implications for Pavlovian conditioning. Psychological Bulletin 86(3):523-548. CrossRef

Risinger, F.O., and C.L. Cunningham. 1998. Ethanolinduced conditioned taste aversion in BXD recombinant inbred mice. Alcoholism: Clinical and Experimental Research 22:1234-1244. CrossRef

Roll, D.L., and J.C. Smith. 1972. Conditioned taste aversion in anesthetized rats. In M.E.P. Seligman and J.L. Hager, editors. Biological foundations of learning. New York: Appleton-Century-Crofts.

Russell, D.A. 1979. The enigma of the extinction of the dinosaurs. Annual Review of Earth and Planetary Sciences 7(1):163-182. CrossRef

Sakamoto, M., Benton, M.J., and C. Venditti. 2016. Dinosaurs in decline tens of millions of years before their final extinction. Proceedings of the National Academy of Sciences 113(18):5036-5040. CrossRef

Schoene, B., Samperton, K.M., Eddy, M.P., Keller, G., Adatte, T., Bowring, S.A. et al. 2015. U-Pb geochronology of the Deccan Traps and relation to the end-Cretaceous mass extinction. Science 347(6218): 182. CrossRef

Schulte, P., Alegret, L., Arenillas, I., Arz, J.A., Barton, P.J., Bown, P.R. et al. 2010. The Chicxulub Asteroid impact and mass extinction at the CretaceousPaleogene Boundary. Science 327(5970):1214. CrossRef

Seligman, M.E.P. and J.L. Hager. 1972. Biological boundaries of learning. The sauce-bearnaise syndrome. Psychology Today 6:59-61 and 84-87.

Sloan, R.E., Rigby, J.K., Van Halen, L.M., and D. Gabriel. 1986. Gradual dinosaur extinction and simultaneous ungulate radiation in the Hell Creek Formation. Science 232(4750):629. CrossRef

Swain, T. 1976. Angiosperm-reptile coevolution. Linnean Society Symposium Series 3:107-122.

Tewksbury, J.J., and G.P. Nabhan. 2001. Directed deterrence by capsaicin in chillies. Nature 412:403. CrossRef

Toon, O.B., Turco, R.P., Robock, A., Bardeen, C., Oman, L., and G.L. Stenchikov. 2007. Atmospheric effects and societal consequences of regional scale nuclear conflicts and acts of individual nuclear 
terrorism. Atmospheric Chemistry and Physics 7(8): 1973-2002. CrossRef

Vellekoop, J., Esmeray-Senlet, S., Miller, K.G., Browning, J.V., Sluijs, A., van de Schootbrugge, B., et al. 2016. Evidence for Cretaceous-Paleogene boundary bolide "impact winter" conditions from New Jersey, USA. Geology 44(8):619-622. CrossRef

Wilcoxon, H.C., Dragoin, W.B., and P.A. Kral. 1971. Illness-induced aversions in rat and quail: Relative salience of visual and gustatory cues. Science 171(3973):826. CrossRef 